\title{
HORIZONTE
}

Apresentação - Dossiê: Paradigma Pós-religional

(9) $\odot \Theta \Theta$

\section{Horizonte, v. 13, n. 37, Jan./Mar. 2015}

\section{Dossiê: Paradigma Pós-religional \\ Dossier: Post-religional Paradigm}

Paulo Agostinho N. Baptista *

Editor-gerente

Com o objetivo de atender à missão de Horizonte de "veicular trabalhos científicos que contribuam para o avanço da pesquisa, especialmente na área das Ciências da Religião e da Teologia, para a formação acadêmica crítica e integral, aberta ao diálogo, à perspectiva interdisciplinar e à pluralidade de ideias", o tema deste dossiê é extremamente polêmico e provocante: "Paradigma Pós-religional". Quer recolocar em debate uma questão que a Comissão Teológica da Associação Ecumênica dos Teólogos(as) do Terceiro Mundo (ASETT/EAWOT) lançou numa consulta geral em 2012, através da revista VOICES (EATWOT, 2012)1: "Para um paradigma pós-religional?”. Certamente, irá suscitar muitas reflexões e pesquisas na área das Ciências da Religião e da Teologia. Nossa seção “Temática Livre” estará aberta a acolher essas reações acadêmicas para enriquecer esse debate.

De modo especial, agradecemos ao teólogo José María Vigil, que realizou a residência pós-doutoral na PUC Minas em 2014, pela dedicação e trabalho que tornaram possível esse dossiê, através de contatos com autores, tradução e acompanhamento da submissão dos textos. Esse agradecimento também se

\footnotetext{
* Doutor e mestre em Ciência da Religião (UFJF), professor adjunto da PUC Minas (graduação e mestrado), editor-gerente de Horizonte. País de origem: Brasil. E-mail: pagostin@gmail.com.

${ }^{1}$ Para acesso a EAWOT, 2012: VOICES, Jan./Mar. 2012): Disponível em:

<http://internationaltheologicalcommission.org/VOICES/VOICES-2012-1.pdf>. Acesso em 30 de março de 2015.
} 
estende a todos(a) os(as) autores(as) que se interessaram pela temática e enviaram suas contribuições.

O dossiê está composto por quatorze Artigos, sete Comunicações e sete Resenhas. Há diversidade de abordagens, de titulação e de lugares geográficos dos(as) autores(as) - de quase vinte países -, com filiações religiosas ou sem filiações religiosas. Em razão dessa situação diversa, e dado à importância e o objetivo de trazer essa temática ao debate e provocar reflexões e novas pesquisas, Horizonte teve uma abordagem editorial mais flexível e diferente de sua rotina. $\mathrm{O}$ que não mudou foi sua preocupação com a qualidade. Alguns textos, com pequenas partes publicadas ou divulgadas em outra língua, tiveram atualização ou complementação, ou ainda foram traduzidos, adequando-se às exigências de originalidade e ao padrão da revista. Alguns textos são oferecidos em mais de uma versão linguística. Por esses motivos, tivemos um dossiê com mais de seiscentos e cinquenta páginas. As seções Temática Livre e Dissertações/Teses foram mantidas em respeito às submissões realizadas fora do tema do dossiê.

Para facilitar o entendimento do tema pelos leitores que não conhecem o conceito "pós-religional”, na perspectiva da Comissão Teológica Internacional da ASETT/EAWOT, essa categoria não deve ser compreendida como

\footnotetext{
"pos-religioso", porque continuará siendo "religioso" en el sentido normal del diccionario, en cuanto "relacionado con la dimensión espiritual del ser humano y de la sociedade", aunque cambien las culturas y las épocas; lo llamamos pos-religional porque ciertamente se instalará en la superación de la citada configuración de lo religioso (aquellos modos de funcionar a los que luego nos vamos a referir propios de las religiones que genéricamente llamamos "agrarias" incluyendo ahí las ganaderas y otras formas más especializadas-). El prefijo «pos» no lo tomamos en el sentido literalmente temporal (como un «después de») sino en un sentido genéricamente superador: "más allá de". Por ello, igualmente sería válido decir "a-religional", sin posible confusión en la dimensión temporal. "Pos-religional" no significa "pos-religioso" ni "post-espiritual", sino, estrictamente, "más allá de lo religional", es decir, más allá de "lo que han sido las religiones agrarias", o una "religiosidad sin religiones (agrarias)", una espiritualidad sin la "configuración socio-institucionalizada propia de la edad neolítica” (sin programación social, sin sumisión, sin dogmas...). (EATWOT, 2012).
} 
Completando a expressão do tema do dossiê, gostaria de destacar sua importância referindo-me à clássica discussão sobre "mudança de paradigma", a partir do livro de Thomas Kuhn "Estrutura das revoluções científicas" (1962), que ganhou amplitude e transposição no campo teológico com o debate ocorrido em 1983, em Tübingen (Alemanha), num Congresso Teológico Ecumênico Internacional: "Um novo paradigma em Teologia", coordenado por Hans Küng. Daí produziu-se a obra "KÜNG, Hans. Theologie im Aufbruch. München: R. Piper GmbH \& Co. KG, 1987", que foi traduzida e publicada também no Brasil: KÜNG, Hans. Teologia a caminho. São Paulo: Paulinas, 1999. Essa questão também deve estar presente nessa discussão que toca a todos os campos da ciência, da epistemologia, da cultura, inclusive à teologia e à religião.

O primeiro artigo do dossiê, de Lee Cormie, trata diretamente de mudança de paradigma: The end of the world as we know it: changing geographies of ignorance and knowledge, hope and faith (O fim do mundo como nós o conhecemos: mudando geografias da ignorância e do conhecimento, esperança e fé). O artigo seguinte, de Marià Corbí, discute La construción del proyecto axiológico coletivo desde el paradigma postreligional. E o terceiro artigo aborda a resposta a um questionamento de Pierre Simon Arnold Gulikers: ¿Un Cristianismo posreligional?

John Shelby Spong, no quarto artigo, retoma sua postulação de doze teses que têm a intenção de refletir sobre uma nova reforma: The twelve theses: a call to a new reformation. O texto representa uma síntese original atualizada das questões centrais de seu livro de 1998: Why Christianity must change or die (Por que o Cristianismo deve mudar ou morrer). Questão próxima está presente no quinto artigo, de Roger Lenaers: Can Christianity and modernity go together? (Cristianismo e modernidade podem andar juntos?). Também com uma pergunta, o sexto artigo, de Juan Masiá provoca reflexão a partir da realidade asiática e japonesa: ¿Fe neo-religiosa, post-religiosa o inter-religiosa? 
Discutindo a questão epistemológica, Sergio Osório apresenta o sétimo artigo: Epistemologia axiológica y conocimiento transdisciplinar: estrategias cognoscitivas para el reconocimiento y cultivo de la cualidad humana profunda $y$ la dimensión sagrada de la existencia.

O artigo oitavo, de Geraldina Céspedes, discute a situação das religiões diante das mudanças de paradigma: Entrar en la danza o desaparecer de la escena: las religiones ante los câmbios de paradigma. E das Filipinas, Daniel Franklin Estepa Pilário traz sua reflexão no nono artigo, também em forma de pergunta: A Ásia é uma sociedade pós-religional? - Is Asia a 'Post-Religional' society? The Post-Religional Paradigm and its others. E a seguir, José María Vigil nos apresenta o artigo Recentrando el papel futuro de la religión: humanizar la Humanidad. El papel de la religión en la sociedad futura va a ser netamente espiritual.

Também autores brasileiros ou que atuam no Brasil participaram desse dossiê. O décimo primeiro artigo é de Faustino Teixeira: A salvaguarda da diversidade e a defesa da criação. A seguir temos $A$ religião sob o domínio da estética, que tem a autoria de Alberto da Silva Moreira. Márcio Antonio de Paiva é autor do décimo terceiro artigo: Da veritas à caritas: a religião depois da religião. E fechando o dossiê, Helmut Renders discute no décimo quarto artigo $A$ experiência religiosa pós-moderna e o fenômeno da aceleração em comparação com as temporalidades pré-moderna e moderna.

Quatro artigos compõem a seção Temática Livre: $A$ imagem da esposa de Cristo na teologia de Balthasar, de Geraldo Luiz Borges Hackmann; A melodia da flauta: a vivência da mística no contexto contemporâneo, de Luiz Síveres; $A$ literatura europeia entre a fábula religiosa indiana e um Buda defraudado, de Arilson Silva Oliveira; e Os caminhos da salvação e da condenação eternas: a presença da alegoria na História do Predestinado Peregrino e de seu Irmão Precito (1682), de Alexandre de Gusmão, de José Adriano Filho. 
Este número traz também três resumos de dissertações defendidas na PUC Minas: $A$ infecção da alma: um estudo do combate à imoralidade no jornal " $O$ Diário" no período do Estado Novo, de Albert Drummond Lopes; Sociedade de Teologia e Ciências da Religião (SOTER): constituição, percurso e abordagens, de Gerson Bento Freire; e Aqui se tropeça em Igreja: estudo sobre a relação entre as Igrejas evangélicas do Capelinha, modernidade e secularização à luz da sociologia de Danieèlle Hervieu-Léger, de Júnio dos Reis Moreira.

Há ainda sete resenhas que abordam livros que têm relação com o dossiê: Crepúsculo da religião: aurora da espiritualidade? Reflexão a partir da dissertação 'Aurora de uma espiritualidade sem religião, de José Álvaro Campos Vieira', de Pedro Assis Ribeiro de Oliveira; Resenha do livro de John Shelby Spong: Um novo cristianismo para um novo mundo, de Valmor da Silva; Para que otro mundo sea posible tenemos que hacer posible otro Dios, de José Ignácio Lópes Vigil e María Lópes Vigil; Recensión de la colección de encuentros internacionales (CeTR), de Francesc Torradeflot Freixes; Para uma espiritualidade leiga: Marià Corbí, de Marta Granés Bayona; Afther Buddhism: Synopsis, de Stephen Batchelor; e Religião e ciência: Eduardo Rodrigues da Cruz, de Jair Souza Leal.

Desejamos que todos tenham uma boa leitura e que continuem divulgando Horizonte para novos leitores! 